\title{
Average slip rate at the transition zone on the plate interface beneath the Kii Peninsula, Japan, estimated from deep low-frequency tremors
}

\author{
Ryosuke Ishida $^{1}$, Yoshihiro Hiramatsu ${ }^{2}$, Takanori Matsuzawa ${ }^{3}$, and Kazushige Obara ${ }^{4}$ \\ ${ }^{1}$ Graduate School of Natural Science and Technology, Kanazawa University, Kakuma, Kanazawa, Ishikawa 920-1192, Japan \\ ${ }^{2}$ School of Natural System, College of Science and Engineering, Kanazawa University, Kakuma, Kanazawa, Ishikawa 920-1192, Japan \\ ${ }^{3}$ National Research Institute for Earth Science and Disaster Prevention, 3-1 Tennodai, Tsukuba 305-0006, Japan \\ ${ }^{4}$ Earthquake Research Institute, The University of Tokyo, 1-1-1 Yayoi, Bunkyo-ku, Tokyo 113-0032, Japan
}

(Received September 24, 2012; Revised April 15, 2013; Accepted April 15, 2013; Online published October 9, 2013)

\begin{abstract}
We investigated the average slip rate at the transition zone on the plate interface beneath the Kii Peninsula, Japan, using an empirical method based on a proportional relation of sizes between short-term slow slip events and nonvolcanic deep low-frequency tremors. The estimated average slip rates are $3.0 \pm 0.4 \mathrm{~cm} / \mathrm{yr}, 2.6 \pm 0.4 \mathrm{~cm} / \mathrm{yr}$, and $2.4 \pm 0.4 \mathrm{~cm} / \mathrm{yr}$, in the northern, central, and southern Kii Peninsula, respectively. Values in the northern and the central areas compensate for the difference between the slip deficit rate at the transition zone and the convergence rate of the subducting Philippine Sea plate. The discrepancy among those rates is, however, large in the southern area, suggesting a lateral variation in the proportional relation or the existence of a steady, or quasi-steady, slip.
\end{abstract}

Key words: Deep low-frequency tremor, slow slip event, slip rate, Philippine Sea plate.

\section{Introduction}

Recent seismological and geodetic observations from dense networks have revealed various characteristic phenomena in subduction zones, especially during interseismic periods, such as nonvolcanic deep low-frequency (DLF) tremors (e.g. Obara, 2002), and short-term and long-term slow slip events (SSE) (e.g. Hirose and Obara, 2005). These events are observed at the transition zone between unstable and stable slip zones on the plate interface. They usually exhibit a temporal correlation.

In southwestern Japan, the Philippine Sea plate subducts beneath the Eurasian plate at the Nankai Trough, repeatedly generating great earthquakes (e.g. Ando, 1975). Geodetic observations have revealed that the strength of the locking of the plate interface depends on the depth of the subducting plate. In the Nankai subduction zone, seismogenic faults at depths of 5-25 km are strongly locked, although locking at the transition zone at depths of 25-35 km, where short-term SSEs and nonvolcanic DLF tremors are located, is weaker than at shallow depths (Tabei et al., 2007). A simulation study revealed that the recurrence interval of short-term SSEs becomes short as the occurrence of a great earthquake becomes imminent (Matsuzawa et al., 2010). Monitoring these events is therefore important to elucidate the seismogenic processes related to great earthquakes at the Nankai Trough.

Many researchers have reported various features of DLF tremors such as spatiotemporal coincidence with short-term

Copyright (C) The Society of Geomagnetism and Earth, Planetary and Space Sciences (SGEPSS); The Seismological Society of Japan; The Volcanological Society of Japan; The Geodetic Society of Japan; The Japanese Society for Planetary Sciences; TERRAPUB.

doi:10.5047/eps.2013.04.003
SSEs (Obara et al., 2004) and have reported the cause of DLF tremors as the shear slip process (Shelly et al., 2006; Ide et al., 2007). Based on these features, Hiramatsu et al. (2008) proposed an empirical method to estimate the average slip rate at the transition zone on the plate interface using the DLF tremors. They showed that the average slip rate became higher in the accelerated period of the Tokai long-term SSE (Ozawa et al., 2002). Hirose et al. (2010) applied this method to the DLF tremors of the Shikoku region of southwestern Japan. They found that the average slip rate compensates for the difference between the convergence rate at the trench (Miyazaki and Heki, 2001) and the slip deficit rate at the transition zone (Tabei et al., 2007) of the subducting Philippine Sea plate.

Our previous studies specifically examined the DLF tremors that occur in the deeper extension of the source areas of the assumed Tokai (Hiramatsu et al. 2008) and the assumed Nankai (Hirose et al., 2010) earthquakes. In the present study, we analyzed DLF tremors that correspond to the source area of the assumed Tonankai earthquake to ascertain the average slip rate at the transition zone on the plate interface of the subducting Philippine Sea plate. We also assess the relation among the average slip rate, the convergence rate at the trench, and the slip deficit rate in the transition zone.

\section{Data and Method}

We analyzed waveform data recorded by a nationwide high-sensitivity seismograph network (Hi-net) operated by the National Research Institute for Earth Science and Disaster Prevention (NIED) (Obara et al., 2005) throughout the Japanese islands. We sought data for DLF tremors that occurred in the Kii Peninsula of southwestern Japan dur- 


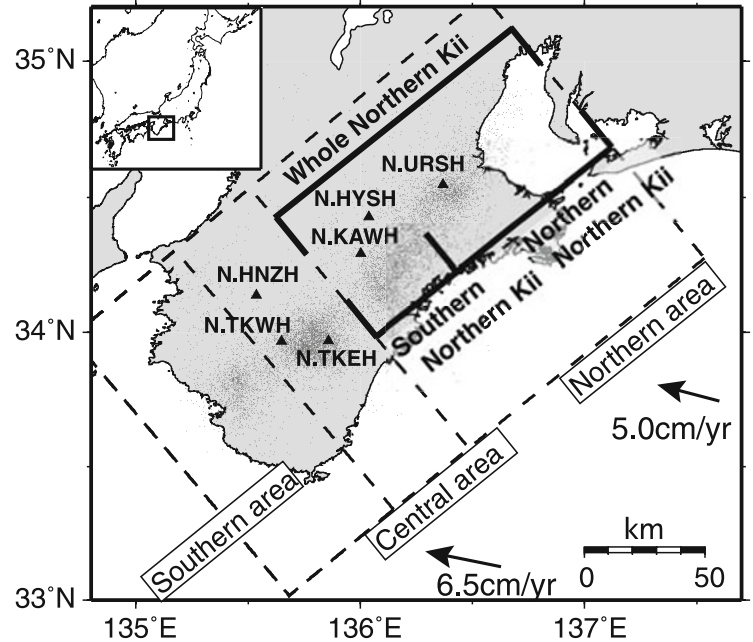

Fig. 1. Distribution of the epicenters of deep low-frequency (DLF) tremors (gray dots) and the Hi-net stations (triangles) providing data used for this study. The distribution is divided into three areas shown by rectangles with dashed lines. The northern area is divided into sub-areas shown by bold lines for the examination of a variation of the conversion factor (Fig. 2). Arrows indicate the convergence rate of the Philippine Sea plate at the trench (Miyazaki and Heki, 2001).

ing January 2001-May 2009. For that search, we used a hypocenter catalog of the DLF tremors determined routinely using the envelope correlation method developed by NIED (Obara, 2002; Obara and Hirose, 2006). This catalogue was used for the estimation of the average slip rate in the transition zones on the plate interface in the Shikoku regions (Hirose et al., 2010).

We divided a belt-like distribution of the DLF tremors on the Kii Peninsula into three segments bounded by the low-activity zones of the DLF tremors: northern, central, and southern areas (Fig. 1). For these analyses, we selected six Hi-net stations on the Kii Peninsula: HYSH, KAWH, and URSH for the northern area, and HNZH, TKEH, and TKWH for the central and southern areas (Fig. 1). They provided high $\mathrm{S} / \mathrm{N}$ waveform data of the DLF tremors during the analyzed period.

We estimated the seismic moment of slip on the plate interface from DLF tremors using the empirical procedure proposed by Hiramatsu et al. (2008). First, we selected the DLF tremors for which the duration of the root-meansquared (RMS) amplitude of ground displacement of the vertical component is greater than the noise level of $>1$ min. The RMS ground displacement was calculated for $2-$ $10 \mathrm{~Hz}$ band-pass filtered displacement waveforms applying the moving average with a time window of $6 \mathrm{~s}$ (Watanabe et al., 2007; Hiramatsu et al., 2008; Hirose et al., 2010). The longest duration observed in this study is $726 \mathrm{~min}$. The average duration is $27.4 \mathrm{~min}$.

Next, we converted the observed velocity waveforms of vertical components to reduced displacements $\left(D_{R}\right)$ (Aki and Koyanagi, 1981). We calculated $D_{R}$ using the formula $D_{R}=A r\left(\mathrm{~m}^{2}\right)$ for body waves, where $A$ is the RMS ground displacement and $r$ is the distance between the source and the receiver because a DLF tremor is composed mainly of $S$ waves (Obara, 2002). We assumed a constant velocity model in the calculation of $r$ because the uncertainty of

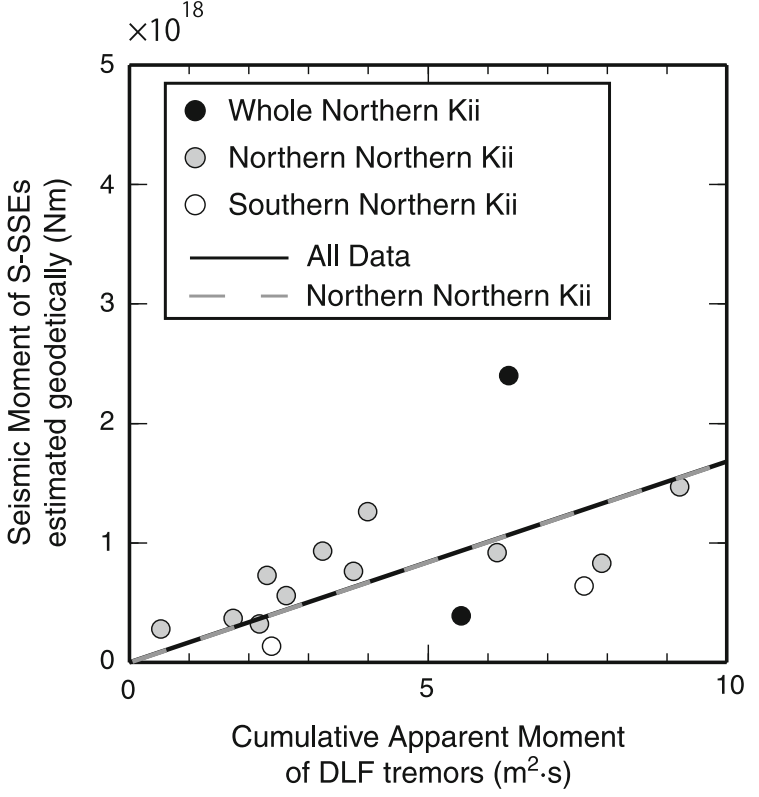

Fig. 2. Plot of the seismic moment of short-term slow slip events (SSEs) observed geodetically (NIED, 2009; Sekine et al., 2010) versus the cumulative apparent moment of a corresponding episode of DLF tremors (circles). The black solid line represents the best-fit line with the slope of $1.7 \times 10^{18} \mathrm{~N} / \mathrm{m} / \mathrm{s}$ for all data in the northern area and the gray dashed line the best-fit line with the slope of $1.7 \times 10^{18} \mathrm{~N} / \mathrm{m} / \mathrm{s}$ for the data in the northern northern Kii area.

source depths of DLF tremors is greater than that of the velocity model (Hirose et al., 2010).

We assume the envelope of $D_{R}$ as the apparent moment rate function, and estimate the event size of a DLF tremor, that is termed as apparent moment, from the average of the time integral of the reduced amplitude over stations (Hiramatsu et al., 2008). We used the seismic moment of 15 short-term SSEs in the northern area as estimated from the records of tiltmeters operated by NIED (NIED, 2009; Sekine et al., 2010) to obtain a conversion factor from the total apparent moment of an episode of the DLF tremors to the seismic moment of a corresponding short-term SSE. Once we obtain the conversion factor, we can estimate the seismic moment of a SSE, even if it is not detected geodetically, by multiplying the conversion factor by the apparent moment estimated from DLF tremors (Hiramatsu et al., 2008; Hirose et al., 2010).

Figure 2 shows that the total size of an episode of the DLF tremors is proportional to the size of a corresponding SSE. The conversion factor estimated from the slope is $1.7 \pm 0.2 \times 10^{17} \mathrm{~N} / \mathrm{m} / \mathrm{s}$ in the northern area. This value is smaller than $3.3 \times 10^{17} \mathrm{~N} / \mathrm{m} / \mathrm{s}$ in the Tokai region (Hiramatsu et al., 2008) and $2.8 \times 10^{17} \mathrm{~N} / \mathrm{m} / \mathrm{s}$ in the Shikoku region (Hirose et al., 2010). The conversion factor is interpreted as being proportional to the inverse of the scaled energy. In other words, it is a ratio of the seismic moment of SSEs to the radiated energy of DLF tremors (Hiramatsu et al., 2008). In the sense of analyses of regular earthquakes, the variation of these values within factors is regarded as constant. However, the value of the conversion factor may vary with the tectonic setting of the subduction zone as the activity of DLF tremors and SSEs varies among subduc- 

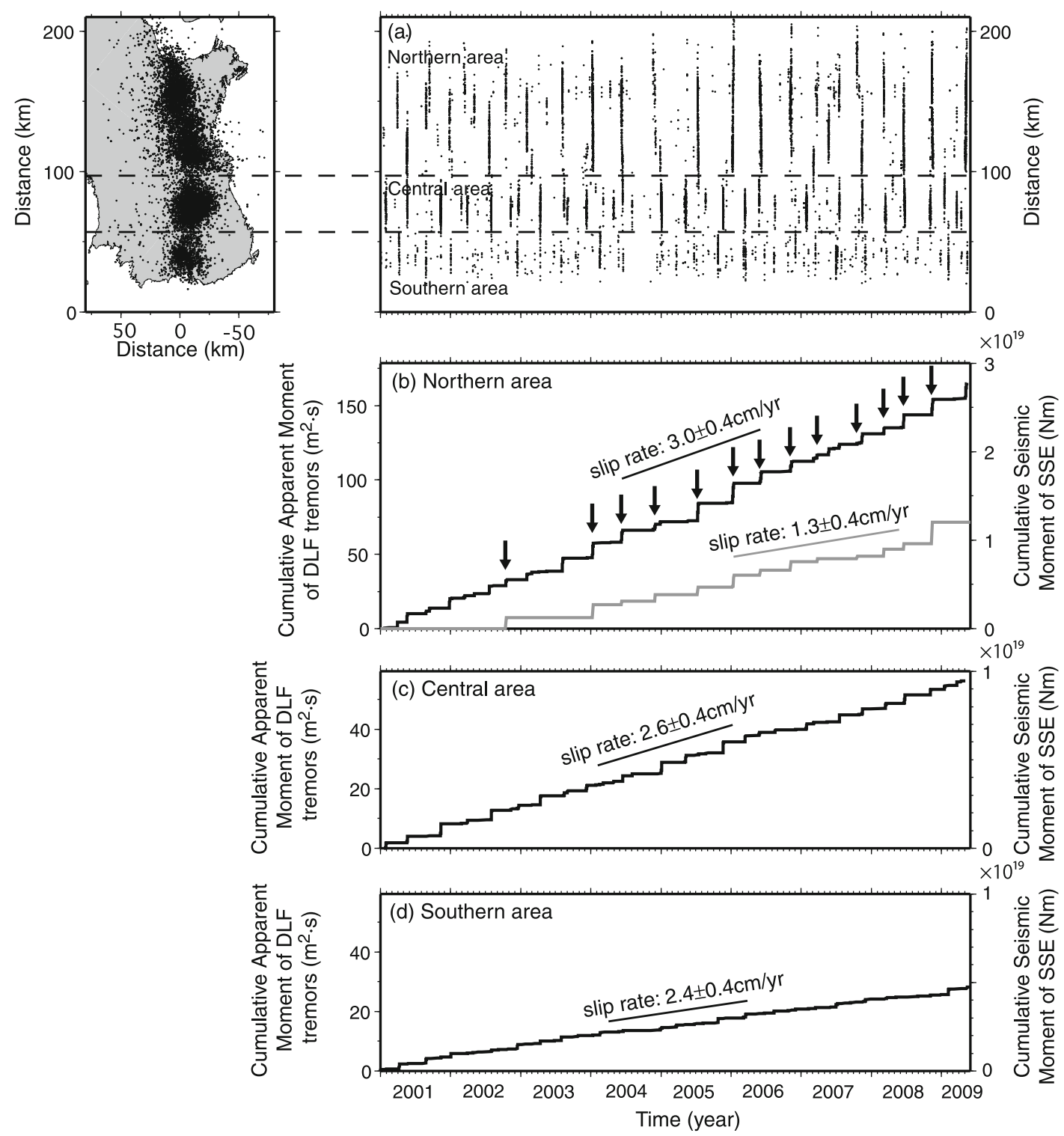

Fig. 3. (a) Time-space distribution of DLF tremors analyzed in this study. (b), (c), and (d) Temporal variations in (left axis) the cumulative apparent moment and (right axis) the cumulative seismic moment (thick black lines) of DLF tremors in the northern, central, and southern areas, respectively. Arrows indicate the occurrence of short-term SSEs observed geodetically in the northern area (NIED, 2009; Sekine et al., 2010). Thin black lines show the average slip rate attributable to short-term SSEs in each region. Gray lines show the average slip rate attributable to short-term SSEs observed geodetically in the northern area.

tion zones. Such a difference may reflect the variation in frictional properties that are controlled by changes in temperature, fluid content, and structural and rheological properties (Obara, 2011), providing a constraint to understand slip phenomena on the plate interface.

The northern area covers a wide area in the Kii Peninsula. Thus, it is important to examine a variation in the conversion factor for a different segmentation. Based on the distribution of the tremors and the fault models of the SSEs in the northern area, we divided the northern area into two sub-areas: the southern northern Kii area and the northern northern Kii area (Fig. 1). The source areas of two SSEs covered the whole area, so we treated those as the whole northern Kii area (Fig. 1). 11 of 15 SSEs occurred in the northern northern Kii area, two in the southern northern Kii area, and two in the whole northern Kii area. Obviously two data are too small to estimate the conversion factor, allow- ing us to estimate the conversion factor from the data in the northern northern Kii area. The estimated conversion factor from the data in the northern northern Kii area is identical with that from all data (Fig. 2).

Unfortunately, no short-term SSE detected geodetically, which is appropriate for an estimation of the conversion factor, was reported in the central and the southern areas. Therefore, we adopted the conversion factor estimated in the northern area for use for DLF tremors in the central and southern areas.

\section{Average Slip Rate on the Plate Interface Esti- mated from DLF Tremors}

We show the temporal variation in the cumulative seismic moment during January 2001-May 2009 at the transition zone on the plate interface in the northern, central, and southern areas estimated from the DLF tremors with 


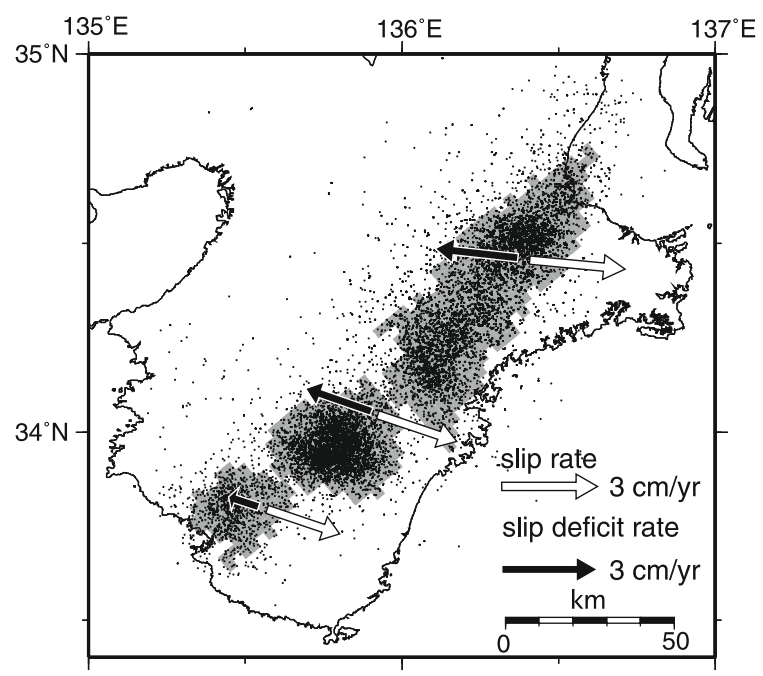

Fig. 4. Dark gray zones are active areas of DLF tremors (dots) used for estimation of the fault area on the plate interface in each area. White arrows indicate the slip rate attributable to short-term SSEs estimated from DLF tremors in this study. Black arrows show the upper limit of the slip deficit rate at the transition zone on the plate interface of the subducting Philippine Sea plate from the Nankai Trough (Kobayashi et al., 2006).

the conversion factor (Fig. 3). The total moment release in the whole period is $2.8 \pm 0.4 \times 10^{19} \mathrm{~N} \mathrm{~m}, 9.5 \pm 1.4 \times 10^{18} \mathrm{~N}$ $\mathrm{m}$, and $4.7 \pm 0.7 \times 10^{18} \mathrm{~N} \mathrm{~m}$, in the northern, central, and southern areas, respectively. The steady increase in the cumulative seismic moment provides the long-term average of the moment release rate attributable to short-term SSEs at the transition zone on the plate interface, and, consequently, the slip rate. The estimated moment release rates are $3.3 \pm 0.5 \times 10^{18} \mathrm{~N} \mathrm{~m} / \mathrm{yr}, 1.1 \pm 0.2 \times 10^{18} \mathrm{~N} \mathrm{~m} / \mathrm{yr}$, and $5.6 \pm 0.8 \times 10^{17} \mathrm{~N} \mathrm{~m} / \mathrm{yr}$, in the northern, central, and southern areas, respectively (Fig. 3). The total moment release, as well as the moment release rate, as estimated from the DLF tremors, is larger than that $\left(1.2 \times 10^{19} \mathrm{~N} \mathrm{~m}\right)$ estimated from the short-term SSEs detected geodetically (Fig. 3).

In the estimation of these values, we include all DLF tremors used for this study. Some small and isolated DLF tremors might not be related to the slip on the plate interface. It is nevertheless readily apparent that those tremors contribute little to the estimation even if they exist. Several SSEs throughout the world have no temporal correlation with DLF tremors (e.g. Schwartz and Rokosky, 2007). Major short-term SSEs in southwestern Japan apparently accompany the activity of DLF tremors. However, if some short-term SSEs with no DLF tremors in the Kii Peninsula exist, then our estimation provides lower limits of the moment release and the moment release rate.

To estimate the slip rate $\dot{U}$ at the transition zone from the moment release rate $\dot{M}_{\mathrm{o}}$, we use the formula $\dot{M}_{\mathrm{o}}=\mu \dot{U} S$, where $S$ denotes the fault area that is related to the slip of short-term SSEs in each area, and $\mu$ is the rigidity. To set the fault area, we approximate that the fault area is equal to the active area of the DLF tremors (Fig. 4). We set $3 \mathrm{~km} \times 3$ $\mathrm{km}$ blocks on the surface and counted blocks in which the number of the epicenters of DLF tremors is $>5$ (Hirose et al., 2010). We then calculated the area of those blocks projected on the plate interface with a dip of $20^{\circ}$, which is the average dip of the source faults of the short-term SSEs observed geodetically (NIED, 2009; Sekine et al., 2010). The estimated fault areas are $2.8 \times 10^{9} \mathrm{~m}^{2}, 1.1 \times 10^{9} \mathrm{~m}^{2}$, and $5.9 \times 10^{8} \mathrm{~m}^{2}$, in the northern, central, and southern areas, respectively (Fig. 4). Assuming a rigidity of $40 \mathrm{GPa}$ (Hiramatsu et al, 2008; Hirose et al., 2010; Sekine et al., 2010), we obtain slip rates of $3.0 \pm 0.4 \mathrm{~cm} / \mathrm{yr}, 2.6 \pm 0.4 \mathrm{~cm} / \mathrm{yr}$, and $2.4 \pm 0.4 \mathrm{~cm} / \mathrm{yr}$, respectively, in northern, central, and southern areas at the transition zone on the plate interface during the analyzed period. However, these estimations depend clearly on how to estimate the fault areas. For example, $\pm 20 \%$ changes of the threshold of the numbers of DLF tremors per block bring $\pm 10-15 \%$ changes of the slip velocity.

\section{Discussion and Concluding Remarks}

In the previous section, we estimated the average slip rate at the transition zone on the plate interface beneath the Kii Peninsula. In terms of the slip rate at the transition zone, the slip deficit rate on the plate interface is an important parameter estimated from GPS data. Hirose et al. (2010) emphasized that the average slip rate estimated from DLF tremors compensates for the difference between the slip deficit rate and the convergence rate of the Philippine Sea Plate beneath the Shikoku region. It is therefore interesting to compare these quantities in the Kii Peninsula.

Kobayashi et al. (2006) analyzed GPS data for the period 2001-2004 and reported that the slip deficit rate at a depth of around $30 \mathrm{~km}$ on the plate interface was $2.2-2.6 \mathrm{~cm} / \mathrm{yr}$, $1.0-2.2 \mathrm{~cm} / \mathrm{yr}$, and $1.0 \mathrm{~cm} / \mathrm{yr}$, in the northern, central, and southern areas, respectively. The ranges of the slip deficit rates in the northern and central areas arise from the difference of the fault segmentation on the plate interface between this study and Kobayashi et al. (2006). The overlap of the analyzed periods and the constant slip rate through the period (Figs. 3(b)-3(d)) enable us to compare the slip rates at the transition zone estimated from different data and methods.

The convergence rate of the Philippine Sea (PHS) plate in this region is estimated to be about $5.0-7.0 \mathrm{~cm} / \mathrm{yr}$ (Miyazaki and Heki, 2001). The differences between the slip deficit rate and the convergence rate of the subducting plate are estimated as $2.4-4.8 \mathrm{~cm} / \mathrm{yr}, 2.8-6.0 \mathrm{~cm} / \mathrm{yr}$, and $4.0-6.0 \mathrm{~cm} / \mathrm{yr}$, in the northern, central, and southern areas, respectively. The value of the difference in the northern area is coincident with the slip rate estimated from the DLF tremors. Therefore, we infer that the strain at the transition zone attributable to the subduction of the PHS plate is partially stored as the slip deficit and that it is partially released by short-term SSEs in the interseismic period beneath the northern Kii area and the Shikoku region. The average slip rate in the central area is slightly smaller than the difference, although these values are mutually consistent within the error. Consequently, this result may be interpreted as equivalent to that for the northern area.

The average slip rate, however, differs significantly from the difference between the slip deficit rate and the convergence rate in the southern area, suggesting two possibilities. One is that the assumption of the constant conversion fac- 
tor breaks in the southern Kii area. Obara (2010) argued the spatial variation in the excitation efficiency of the DLF tremors because of short-term SSEs. If the conversion factor in the southern area is twice as large as that estimated, then we obtain a coincident value of the average slip rate with the difference. Alternatively, the threshold to define the fault area is inadequate for the southern area; that is, the fault area may be a half of that estimated. The other is that a steady, or quasi-steady, slip occurs at the transition zone, as suggested from some observation and simulation studies. Kobayashi et al. (2006) reported that the slip deficit rate in the southern area is much smaller than those of other areas, implying a steady, or quasi-steady, slip that releases the strain. For the 2011 off the Pacific coast of Tohoku earthquake, Suito et al. (2011) reported that the transient slips following M 7-class earthquakes in 2008 and 2010 were pre-seismic signals of the giant earthquake. A numerical simulation study shows that a combination of frictional parameters reproduces not only this feature but also a longterm slip, of which the rate is the same order of the convergence rate, before a giant earthquake (Hori and Miyazaki, 2011). If this kind of long-term steady, or quasi-steady, slip occurs actually in the southern area, the geodetic estimation of the slip deficit rate may be smaller than that with no steady, or quasi-steady, slip and the mismatch between the average slip rate, the slip deficit rate and the convergence rate can be resolved.

The procedure to estimate slip velocity on the plate interface as the long-term average from DLF tremors presented here is easily applicable to other subduction zones, if sufficient data is available. Future works will illustrate the universality or the difference of the parameters estimated in this study and will provide clues to understand slip phenomena in subduction zones.

Acknowledgments. We are grateful to the National Research Institute for Earth Science and Disaster Prevention for providing us with the hypocentral and waveform data of the DLF tremors. We thank Hitoshi Hirose and Shutaro Sekine for providing data for slow slip events. Comments from anonymous reviewers helped to improve the manuscript. GMT software (Wessel and Smith, 1998) was used to produce all the figures.

\section{References}

Aki, K. and R. Y. Koyanagi, Deep volcanic tremor and magma ascent mechanism under Kilauea, Hawaii, J. Geophys. Res., 86, 7095-7109, 1981.

Ando, M., Source mechanisms and tectonic significance of historical earthquakes along the Nankai Trough, Japan, Tectonophysics, 27, 119-140, 1975.

Hiramatsu, Y., T, Watanabe, and K. Obara, Deep low-frequency tremors as a proxy for slip monitoring at plate interface, Geophys. Res. Lett., 35, L13304, doi:10.1029/2008GL034342, 2008.

Hirose, H. and K. Obara, Repeating short- and long-term slow slip events with deep tremor activity around the Bungo Channel region, southwest Japan, Earth Planets Space, 57, 961-972, 2005.

Hirose, T., Y. Hiramatsu, and K. Obara, Characteristics of short-term slow slip events estimated from deep low-frequency tremors in Shikoku, Japan, J. Geophys. Res., 115, B10304, doi:10.1029/2010JB007608, 2010 .
Hori, T. and S. Miyazaki, A possible mechanism of $M 9$ earthquake generation cycles in the area of repeating $M 7 \sim 8$ earthquakes surrounded by aseismic sliding, Earth Planets Space, 63, 773-777, 2011.

Ide, S., D. R. Shelly, and G. C. Beroza, The mechanism of deep low frequency earthquakes: further evidence that deep non-volcanic tremor is generated by shear slip on the plate interface, Geophys. Res. Lett., 34, L03308, doi:10.1029/ 2006GL028890, 2007.

Kobayashi, T., M. Hashimoto, and T. Tabei, Estimate of interplate coupling along the Nankai Trough, southwest Japan, using a new plate interface model, Eos Trans. AGU, 87, Fall Meet. Suppl., Abstract S43D-7, 2006.

Matsuzawa, T., H. Hirose, B. Shibazaki, and K. Obara, Modeling short- and long-term slow slip events in the seismic cycles of large subduction earthquakes, J. Geophys. Res., 115, B12301, doi:10.1029/2010JB007566, 2010.

Miyazaki, S. and K. Heki, Crustal velocity field of southwest Japan: Subduction and arc-arc collision, J. Geophys. Res., 106, 4305-4326, 2001.

National Research Institute for Earth Science and Disaster Prevention, Short-term slow slip event with non-volcanic tremors in southwest Japan (November, 2008-April, 2009), Rep. Coord. Comm. Earthq. Predict. Jpn., 82, 392-397, 2009.

Obara, K., Nonvolcanic deep tremor associated with subduction in southwest Japan, Science, 296, 1679-1681, 2002.

Obara, K., Phenomenology of deep slow earthquake family in southwest Japan: Spatiotemporal characteristics and segmentation, J. Geophys. Res., 115, B00A25, doi:10.1029/2008JB006048, 2010.

Obara, K., Characteristics and interactions between non-volcanic tremor and related slow earthquakes in the Nankai subduction zone, southwest Japan, J. Geodyn., 52, 229-248, 2011.

Obara, K. and H. Hirose, Non-volcanic deep low-frequency tremors accompanying slow slips in the southwest Japan subduction zone, Tectonophysics, 417, 33-51, 2006.

Obara, K., H. Hirose, F. Yamamizu, and K. Kasahara, Episodic slow slip events accompanied by non-volcanic tremors in southwest Japan subduction zone, Geophys. Res. Lett., 31, L23602, doi:10.1029/2004GL020848, 2004.

Obara, K., K. Kasahara, S. Hori, and Y. Okada, A densely distributed highsensitivity seismograph network in Japan: Hi-net by National Research Institute for Earth Science and Disaster Prevention, Rev. Sci. Instrum., 76, 021301, doi:10.1063/1.1854197, 2005.

Ozawa, S., M. Murakami, M. Kaidzu, T. Tada, T. Sagiya, Y. Hatanaka, H. Yarai, and T. Nishimura, Detection and monitoring of ongoing aseismic slip in the Tokai region, central Japan, Science, 298, 1295-1298, 2002.

Schwartz, S. Y. and J. M. Rokosky, Slow slip events and seismic tremor at circum-Pacific subduction zones, Rev. Geophys., 45, RG3004, doi:10.1029/2006RG000208, 2007.

Sekine, S., H. Hirose, and K. Obara, Along-strike variations in short-term slow slip events in the southwest Japan subduction zone, J. Geophys. Res., 115, B00A27, doi:10.1029/2008JB006059, 2010.

Shelly, D. R., G. C. Beroza, S. Ide, and S. Nakamura, Low-frequency earthquakes in Shikoku, Japan and their relationship to episodic tremor and slip, Nature, 442, 188-191, 2006.

Suito, H., T. Nishimura, M. Tobita, T. Imakiire, and S. Ozawa, Interplate fault slip along the Japan Trench before the occurrence of the 2011 off the Pacific coast of Tohoku Earthquake as inferred from GPS data, Earth Planets Space, 63, 615-619, 2011.

Tabei, T., M. Adachi, S. Miyazaki, T. Watanabe, and S. Kato, Interseismic deformation of the Nankai subduction zone, southwest Japan, inferred from three-dimensional crustal velocity fields, Earth Planets Space, 59, 1073-1082, 2007.

Watanabe, T., Y. Hiramatsu, and K. Obara, Scaling relationship between the duration and the amplitude of non-volcanic deep low frequency tremors, Geophys. Res. Lett., 34, L07305, doi:10.1029/2007GL029391, 2007.

Wessel, P. and W. H. F. Smith, New, improved version of Generic Mapping Tools released, Eos Trans. AGU, 79, 579, 1998.

R. Ishida, Y. Hiramatsu (e-mail: yoshizo@hakusan.s.kanazawau.ac.jp), T. Matsuzawa, and K. Obara 